
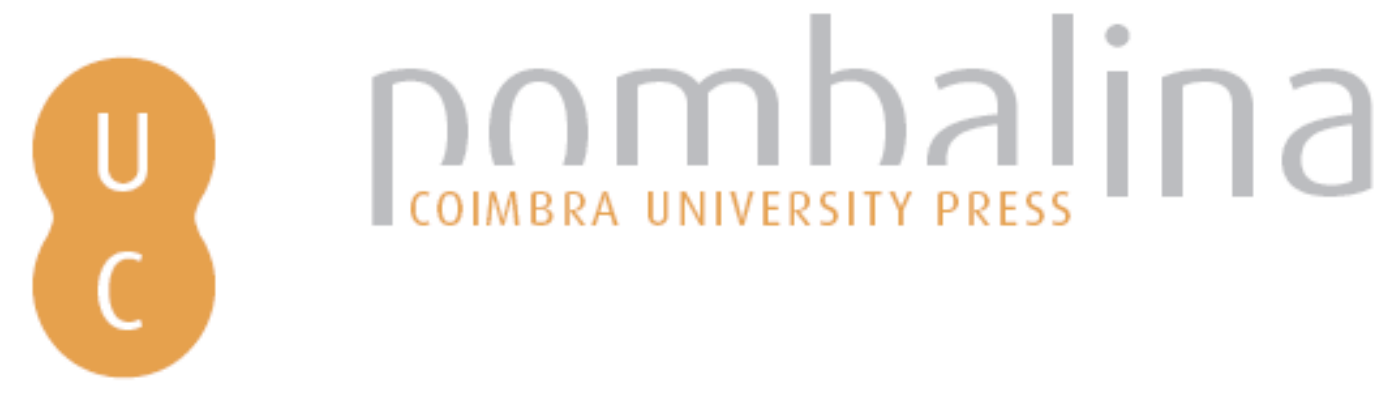

\title{
Teoria crítica, prática geográfica e desenvolvimento local
}

Autor(es): $\quad$ Azevedo, Ana Francisca de

Publicado por: Imprensa da Universidade de Coimbra

URL

persistente:

URI:http://hdl.handle.net/10316.2/30804

DOI:

DOI:http://dx.doi.org/10.14195/978-989-26-0244-8_33

Accessed : $\quad$ 26-Apr-2023 14:37:04

A navegação consulta e descarregamento dos títulos inseridos nas Bibliotecas Digitais UC Digitalis, UC Pombalina e UC Impactum, pressupõem a aceitação plena e sem reservas dos Termos e Condições de Uso destas Bibliotecas Digitais, disponíveis em https://digitalis.uc.pt/pt-pt/termos.

Conforme exposto nos referidos Termos e Condições de Uso, o descarregamento de títulos de acesso restrito requer uma licença válida de autorização devendo o utilizador aceder ao(s) documento(s) a partir de um endereço de IP da instituição detentora da supramencionada licença.

Ao utilizador é apenas permitido o descarregamento para uso pessoal, pelo que o emprego do(s) título(s) descarregado(s) para outro fim, designadamente comercial, carece de autorização do respetivo autor ou editor da obra.

Na medida em que todas as obras da UC Digitalis se encontram protegidas pelo Código do Direito de Autor e Direitos Conexos e demais legislação aplicável, toda a cópia, parcial ou total, deste documento, nos casos em que é legalmente admitida, deverá conter ou fazer-se acompanhar por este aviso.

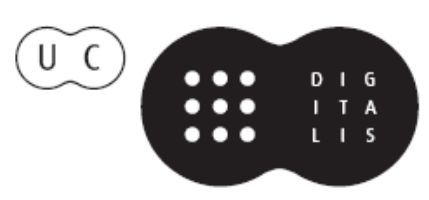




\section{TRUNFOS DE UMA}

\section{EOGRAFIA ACIVA}

\section{DESENVOLVIMENTO LOCAL,}

AMBIENTE,

ORDENAMENTO

E TECNOLOGIA

Norberto Santos

Lúcio Cunha

COORDENAÇÃO 
Ana Francisca de Azevedo

Departamento de Geografia, Universidade do Minho

TEORIA CRÍTICA, PRÁTICA GEOGRÁFICA E DESENVOLVIMENTO LOCAL

\section{INTRODUÇÃO}

O presente artigo discute a ideia de 'geografia activa' perspectivada como uma geografia crítica e de pendor emancipatório.

Tem por objectivo mostrar a íntima relação entre tecnologia e desenvolvimento, entendendo-se a produção de conhecimento como tecnologia para a organização da experiência e, tendo em conta, uma complexa genealogia histórica do desenvolvimento que percorre o pensamento ocidental. Uma história que envolve teorias e práticas do território.

Tem ainda como objectivo a discussão do papel dos mecanismos de conhecimento local como dimensão central para a resolução da crise do sistema de acção comunicativa e como elemento crucial das políticas de ordenamento.

\section{TEORIA CRÍTICA E POLÍTICAS DE TERRITORIALIZAÇÃO}

O desenvolvimento de abordagens críticas em Geografia alicerçadas no contributo das reformulaçóes do materialismo histórico têm vindo a deslocar-se bem para além das prioridades da economia política ortodoxa, no sentido de incorporar, em igual medida, as preocupaçôes provenientes da filosofia, da estética e das teorias culturais emergentes.

Aquilo de que se trata é de desenvolver estudos que permitam a recolocação das problemáticas espaciais tendo em conta as reconstruçóes do materialismo histórico, mas tendo ainda em conta o contributo das abordagens pós-estruturalistas e pós-coloniais bem como dos Estudos Culturais, Estudos de Género, entre outros.

Juntamente com outros autores que proporcionaram bases sólidas para a reconsideração das problemáticas espaciais, Habermas desenvolveu uma teoria segundo a qual a crítica epistemológica só é possível se entendida como uma teoria social. Especificamente, o seu trabalho em torno do conceito de 'interesses cognitivos' ou 'constituintes do conhecimento', ao surgir como central para a compreensão da ideia de 'trabalho social' configura-se como determinante para a compreensão das modernas espacialidades. Essa ideia organiza-se através de duas componentes ; 1) o sistema de acção instrumental que envolve a realização de um interesse técnico (controlo de materiais e componentes), e 2) a interacção social que envolve a realização de um interesse prático (meio de assegurar a compreensão mútua dos participantes). 
Percebidas como duas formas de conhecimento diferentes mas interdependentes, estas componentes organizam-se através de um sistema de acção comunicativa estruturado em duas grandes categorias de conhecimento; as ciências empírico-analíticas e as ciências histórico-hermenêuticas. Ora, para Habermas, uma ciência crítica deve deslocar-se em direcção a uma terceira via, uma via de emancipação que envolve a conjugação destas duas formas de conhecimento (Habermas, 1975, 1979) para a resolução dos problemas sociais e espaciais gerados pelas sociedades modernas capitalistas. Mas, esta $3^{\text {a }}$ via, inclui ainda os aportes de instâncias alternativas de produção de conhecimento.

De facto, e como foi extensivamente sublinhado por autores como David Harvey, a passagem do fordismo para a acumulação flexível trouxe consigo sérios problemas sociais e de organização do trabalho produzindo complexas espacialidades e dramáticos desarranjos ao nível do ordenamento territorial. A racionalidade instrumental dos sistemas sociais, legitimada pela crença dominante na ideia de conhecimento técnico útil, conduziu, no limite, a uma crise dos sistemas de acçáo comunicativa, confinado o próprio acto de comunicação à acção mediadora dos centros de produção de conhecimento, encarados como poderosos agentes e aparatos hegemónicos.

Para analisar o problema do ordenamento do território é necessário ter em conta esta crise dos sistemas de acção comunicativa que se exprime através das práticas de lugar, bem como a reprodução simbólica dos mundos da experiência de diferentes indivíduos e grupos. É necessário, enfim, atender aos processos generativos de revisão epistemológica, de re-escrita ontológica e de questionamento dos quadros relacionais que póe em contacto teoria e prática geográfica.

A despeito da alerta de inúmeros autores e autoras para a necessidade de compreensão da importância das redes de conexão e diferença que se articulam através do espaço, e para a urgência de um remapeamento da territorialidade das batalhas sociais, está ainda muito trabalho por fazer no que respeita à compreensão das redes de produção do espaço responsáveis pela subjugação de identidades locais alternativas. A este propósito, a teoria de Henry Lefebvre, apresentando inúmeras divergências relativamente à teoria de Habermas, representa um valoroso contributo para a compreensão dos constrangimentos histórico-geográficos da produção de conhecimento, clarificando os mecanismos de sobreposição de um espaço abstracto e absoluto sobre um espaço físico e heterogéneo mais aberto à emancipação e à diferença.

A meados da década de 1980 começaram a fazer sentir-se transformaçóes importantes na natureza dos sistemas de produção e competição capitalista e, paralelamente, severas críticas dirigidas aos centros de produção de conhecimento levaram à organização de movimentos político-intelectuais que vieram a sediar-se dentro da própria Academia. No que respeita à Geografia, a crítica é desferida contra as formas de produção de conhecimento que reificavam uma metageografia global, autorizando formas concretas de intervençáo no território e definindo quem estava autorizado para a gestão do território e para deliberação sobre problemáticas ambientais e de ordenamento. Apontavam-se as fragilidades de instituiçóes que em grande medida se encontravam ao serviço dos grandes grupos económicos, de políticas e ideologias de pendor logocêntrico. Enfim, denunciava-se a incapacidade de abertura à diferença por parte dos centros de produçáo de conhecimento científico e a falência da articulação entre políticas espaciais de diferentes escalas. Mostrava-se como o paradigma moderno de desenvolvimento é sustentado por uma teia de poder, verdade e conhecimento 'naturalizada' através de técnicas e tecnologias de representação que continuamente activam 
um imaginário geográfico dominante. Imaginário que, esse sim, tem vindo a operar à mais diversas escalas e que resulta de um projecto de colonização das representaçóes culturais assente sobre a dicotomia do Eu e do Outro, do sujeito e do objecto, do centro e da periferia. Um projecto que, em última instancia, se virou contra si mesmo, desde logo, por não dar resposta aos problemas de ordem local. $\mathrm{E}$ isto porque:

a) neutralizou a competência para a acção ambiental de cada sujeito político;

b) ignorou os mecanismos de participação activa comunitária na resolução dos problemas de cada fracçáo de território;

c) descorou a criação de redes de parceria inter e intra-institucional (da Família ao Estado)

d) negligenciou o papel dos mediadores de diferentes formas de conhecimento, elementos efectivamente empenhados com a mudança e perspectivados como agentes cruciais nos processos de negociação da acção comunicativa.

Aquilo que está em causa é, portanto, o processo através do qual se foi operando o enviesamento dos sistemas de acção comunicativa à medida que se iam pondo em prática políticas de desenvolvimento. Em vez de uma comunicação dialogante, o processo monológico de comunicação ditado desde um centro e irradiando para as periferias, conduziu os habitantes das localidades factuais à passividade e à inércia, retirando-lhes o sentido de autoridade para agir sobre o território em que habitam. Quem é, afinal, o cultor de cada paisagem?

Tradicionalmente orientada para a reflexão sobre o capitalismo e a modernidade, a teoria crítica de pensamento social e político abriu-se amplamente para questóes espaciais, revistas tendo em conta os aportes de novas teorias culturais. Neste contexto, a Geografia tem vindo a deter importância crucial, dada a intensa dinâmica teórica das últimas décadas que, se, por um lado, veio incrementar a divisão dentro da própria disciplina (métodos e objectos), por outro lado, potenciou uma maior abertura para outras disciplinas e formas de conhecimento teórico-prático.

A discussão de problemáticas ambientais, do ordenamento e desenvolvimento são redimensionadas tendo em conta o carácter transdisciplinar das abordagens que circulam através da Geografia Humana, pela pluralização de narrativas e fontes de conhecimento. Este movimento de espacialização da teoria, directamente implicado com a relação entre teoria e políticas de produçáo de conhecimento serve o propósito de indagar as formas de autoridade envolvidas nas próprias práticas de teorização. Desde este ponto, um 'ponto de fractura' (Barnet, C., 2009) relativamente à natureza essencialista e fundacionalista da ciência ocidental e aos seus preceitos universalistas, o compromisso de muitos geógrafos e geógrafas com uma teoria viajante permite analisar a geografia da própria teoria e aprender com 'outras regióes'.

Para uma disciplina amplamente comprometida com a dimensão prática do conhecimento, com o trabalho empírico e de campo, este é um momento muito especial e um enorme desafio.

Mas, a relação entre Geografia e tradição científica é ambígua dada a sua profunda implicação com o projecto da modernidade. A forma como se foi esgrimindo teoria e prática geográfica encontra-se impregnada pelos ditames de um conhecimento estratégico, que determinaram a prática científica e que legitimaram uma geopolítica evolucionista e do desenvolvimento. Donde a necessidade de inquirir métodos e práticas de produção de conhecimento e de analisar a espacialidade da ciência como prática cultural (Livingstone, 
2003; Pimenta, 2008), por forma a ampliar o espectro da acção comunicativa e do conhecimento local.

\section{PrÁtica GEOGRÁFICA E PARADIGMAS DE DESENVOLVIMENTO}

Indagando o significado da localização para a recepção e produção de conhecimento, atendamos ao modo como se processa o consumo e circulaçáo do conhecimento tendo em conta diferentes paradigmas de desenvolvimento.

Entendida como tecnologia para organização da experiência, a produção do conhecimento sediada nos grandes centros metropolitanos tem nutrido um paradigma de desenvolvimento que remete para uma construção novecentista forjada no quadro de um ideário evolucionista que sustentou noçóes organicistas de crescimento e perspectivas teleológicas da história, da ciência e do progresso do mundo e cultura ocidentais (Watts, M. 2000). Se, inicialmente, estas noçóes de desenvolvimento e progresso funcionavam como uma espécie de discurso organizado, como meio de lidar com as disjuncturas do crescimento capitalista e com a unidade paradoxal da modernidade, com o tempo, e sobretudo com o advento das duas grandes guerras e dos movimentos de descolonização, elas permitiram organizar um paradigma do desenvolvimento assente sobre a dicotomia primeiro/terceiro mundo. Privilegiando o Estado e a sociedade civil de mercado, este paradigma alcançou a sua máxima expressão com as teorias económicas de desenvolvimento, inspirando o reequacionamento dos espaços periféricos e das ex-colónias como mundos em desenvolvimento.

A análise do desenvolvimento como processo histórico singular (Arturo Escobar, 1995) requer uma sensibilidade particular relativamente a aspectos tais como; o processo de construção cultural das regióes, os discursos do global e os quadros relacionais que articulam o poder local. Como forma particular de imaginário social (Escobar, 1995), o desenvolvimento assenta na cristalização de um retrato do mundo, um mundo disposto para ordenamento em que a diferença é escalonada de acordo com valores éticos, morais e estéticos promovidos por um exterior constitutivo. Aquilo que se questiona são as teorias que sustentam tal imagem do mundo, são os aparelhos humanos e não humanos que asseguram a circulação desta representação cultural e são também as práticas de intervençấo decorrentes de um modelo de base universalista, essencialista e fundacionalista que funciona como alicerce para esquemas conceptuais generalizáveis, hierarquias de conhecimento útil destinadas à preservaçáo da utopia do sujeito da modernidade.

Perspectivada como discurso e prática cultural, a noçáo de desenvolvimento apresenta uma caprichosa genealogia (Williams, 1976; Watts, 2003). Se esta ideia surge primeiramente como construçáo cultural de um 'primeiro mundo', a sua disseminação e apropriação coloca-a como um dos edifícios mais reclamados da modernidade pelos dois lados do binómio.

Entendido como versão contemporânea do Orientalismo, como parte de um processo de reconfiguração de uma cultura colonial para uma cultura do desenvolvimento, o Desenvolvimento produziu o seu próprio efeito de espelhamento, sendo rapidamente absorvido pela ortodoxia neo-liberal. As geografias críticas do desenvolvimento, ao conduzirem etnografias das instituiçóes do Desenvolvimento (desde o Banco Mundial às comunidades indígenas, agrarias ou suburbanas de pequena escala), têm necessariamente de analisar um fenómeno multifacetado que não resulta unicamente da acção de um sujeito activo sobre um objecto 
passivo, mas que resulta de processos de reconhecimento mútuo e negociação de subjectividades sobre os quais assenta a negociação das políticas de desenvolvimento.

A desconstruçáo da linguagem do desenvolvimento, tem revelado a complexidade de expressóes que se tornaram correntes tais como desenvolvimento sustentável, questionando o seu papel social e o capital social dos textos e discursos do desenvolvimento. Palavras-chave tais como $1^{\circ}, 2^{\circ}$ e $3^{\circ}$ mundo, ao despoletarem uma contra-reacçáo por parte da crítica pósdesenvolvimentista, são paralelamente esgrimidas em discursos com alargado consenso político, como valorosos recursos para a integração das forças da economia mundial.

Funcionando como quinta-essência das políticas de desenvolvimento, tais classificaçóes profundamente inadequadas de espaço geográfico (e de corpos geográficos), legitimam um dramático ajustamento de mercados ao serviço da ideia de globalização.

Enquanto narrativas da globalizaçáo, as teorias do desenvolvimento são o substrato de práticas institucionais que tentam lidar com a diferença, mas que muito frequentemente funcionam como elemento de homogeneizaçáo da diferença, através de ásperas políticas de exclusão. Donde, a necessidade de reflectir sobre as práticas de produçáo de conhecimento donde emanam narrativas do desenvolvimento. A necessidade de reflectir sobre teorias e práticas do desenvolvimento, respectiva institucionalizaçáo e seus efeitos. Este é um caminho que tem vindo a ser percorrido por geógrafas e geógrafos em diferentes partes do mundo e que permitiu a organizaçáo de um corpus relativamente estabilizado de geografias críticas do desenvolvimento.

\section{CONHECIMENTO SITUADO E DESENVOLVIMENTO LOCAL}

Neste contexto, um dos campos centrais de análise é a produção do conhecimento local. Primeiro, porque um dos elementos centrais de contestação à noção de desenvolvimento radica no facto de esta ser uma construção engendrada pelos centros metropolitanos de produção de conhecimento, os centros de produçáo de teoria científica perspectivados como os nódulos de onde irradia um conhecimento universal. Depois, porque o trabalho das 'comunidades periféricas' tem mostrado que as soluçóes alternativas de conhecimento local são vias de conhecimento que não podem ser descuradas.

Aquilo que está em causa é a assumpção de teoria e prática geográficas como expressão da inovaçáo e do conhecimento local, propondo-se a desconstrução dos discursos de planeamento enredados numa noçáo monolítica de desenvolvimento; a caixa 'des bonbons anciens', o projecto político da modernidade.

A ideia de conhecimento local, assenta na premissa de que todo o conhecimento é geográfica e historicamente situado, irredutivelmente social, e de que as condiçóes locais de fabrico do conhecimento afectam a natureza do próprio conhecimento produzido (Geertz, 1983). Tendo como preocupação central os contextos de produção de conhecimento, a ideia de conhecimento local é mobilizada pelas teorias críticas de desenvolvimento tendo em conta o contexto cultural dentro do qual o conhecimento é produzido bem como as formas de recepção, disseminação e negociação desse mesmo conhecimento. Como salienta Trevor Barnes (2000), (e cito) “o conhecimento que emerge num contexto particular é modelado pelas condiçóes locais e por determinantes históricas e sociais irrepetíveis, por constelaçóes particulares de forças que interferem no seu fabrico e cujos efeitos se repercutem noutros tempos e lugares mas nunca apresentando a mesma combinação". Historicamente preocu- 
pada com as questóes de localização, a ciência geográfica persegue o seu rumo. Não obstante, aquilo que nos ocupa neste momento não é a busca de um conhecimento universal.

A ideia de conhecimento local associada à ideia de conhecimento viajante, alertando para o modo como se opera a deslocação de inúmeras narrativas num mundo hipermediatizado, inviabiliza a ideia de um conhecimento local fixo e imutável. Neste sentido, é necessário analisar as redes de conhecimento concebidas como interacçóes processuais que se deslocam de uns lugares para os outros. É necessário proceder a uma (des)hierarquizaçáo das cadeias de produçáo de conhecimento partindo da premissa de que todo o conhecimento é um conhecimento local, pelo que tentar torná-lo universal é sempre um acto mais ou menos agressivo de artificialização que se encontra em dependência total de comunidades de autorização. Por isso, esta questáo entronca directamente como a dialéctica local-global. Que, a este nível, funciona como uma falsa questão.

Reflectindo as políticas e ideologias que a cada momento determinam o poder de autorização na produção de grandes narrativas, o conhecimento é sempre local e percorrido por interesses sociais e económicos. Orientamo-nos, pois, com Donna Haraway, para a ideia de que ao ser local, todo o conhecimento é parcial e situado e de que qualquer cultura científica deve ser, antes de mais, uma cultura pública. Perspectivada como cultura pública, a ciência abre-se a diferentes formas de conhecimento passíveis de destronar a 'ideologia prometeica' do desenvolvimento (sco), com a sua ansiedade crónica relativamente aos problemas do subdesenvolvimento, ou crescimento desigual. Consciente do desuso do termo 'subdesenvolvimento', gostaria tão somente de notar que o rearranjo dos discursos do desenvolvimento, pela colocação do termo 'em vias de desenvolvimento' só veio atrasar o processo de autodeterminação das áreas sobre as quais recai esta metadesignação, rejeitando as instancias de produção de conhecimento local.

A ventura utópica de articulaçáo do capitalismo neo-liberal e equidade, a moderna obsessão pelo domínio da verdade e pelo controlo das categorias de justiça, mostrou bem que uma como outra têm os seus tempos e espaços de afirmaçáo, cronotopes muito peculiares com fronteiras perfeitamente demarcadas. É nessas fronteiras que se experimentam outras formas de conhecimento, aquilo a que tenho chamado as geografias do sujeito heterogéneo da diferença.

\section{REFERÊNCIAS BIBLIOGRÁFICAS}

Alvarez, C. (1992). Science, Development and Violence. Delhi: Oxford University Press.

Azevedo, A.F., Pimenta, J.R., Sarmento, J. (2009). Geografias do Corpo. Porto: Figueirinhas.

Barnes, T. (2004). A paper related to everything but more related to local thing. Annals, Association of American Geographers, 94: 278-283.

Barnett, C., Robinson, J., Rose, G. eds. (2008). Geographies of Globalization: A Demanding World. London: Sage.

Clayton, D. (2003). Critical Imperial and Colonial Geographies. In Anderson, K. et al eds., Handbook of Cultural Geography. London: Sage, 354-368.

Cowen, M., Sherton, R. (1996). Doctrine of Development. London: Routledge.

Dear, M., Flusty, S. eds (2002). The spaces of postmodernity. London: Blackwell.

Escobar, A. (1995). Encountering development. Princeton: Princeton University Press.

Habermas, J. (1984). The theory of communicative action, Vol. 1: Reason and the rationalization of society. London: Heinemann. 
Haraway, D. (1991). Simians, cyborgs and woman. London: Routledge.

Haraway, D. (2004). The Haraway Reader. London: Routledge.

Holquist, M. ed. (2002). The Dialogic Imagination by M. M. Bakhtin. Texas: University of Texas Press.

Honneth,A., Joas, H. (1991). Communicative action: Essays on Jurgen Habermas's The theory of communicative action. Cambridge, MA: MIT Press.

Katie, W. (2005). Theories and Practices of Development. London: Routledge.

Katz, C. et al (1998). Lost and Found in the posts: addressing critical human geography. Environment and Planning D: Society and Space 16: 257-78.

Latour, B., Porter, C. (2004). Politics of Nature: How to Bring the Sciences into Democracy.

Lefebvre, H. (1992). The production of space. Oxford: Blackwell.

Livingstone, D. (2003). Putting Science in its Place. Chicago: University of Chicago Press.

McEwan, C., Blunt, A. (2002). Postcolonial Geographies. London: Continuum.

McGregor, A. (2009). New Possibilities? Shifts in Postdevelopment Theory and Practice.

Miller, B. (1992). Collective action and rational choice: Place, community and the limits to individual self interest. Economic Geography 68: 22-24.

Mitchell, K. (2003). Cultural Geographies of Transnationality. In Anderson, K. et al eds., Handbook of Cultural Geography. London: Sage, 74-88.

Pimenta, J.R., Sarmento, J., Azevedo, A.F. (2007). Geografias Póscoloniais. Porto: Figueirinhas.

Pimenta, R. (2008). O Lugar do Passado em Martins Sarmento. Porto: Figueirinhas.

Potter, R. B. et al eds (2008). Geographies of Development: An Introduction to Development Studies. London: Pearson.

Preston, D. (1996). Development theory. Oxford: Blackwell.

Probyn, E. (2003). The Spatial Imperactive of Subjectivity. In Anderson, K. et al eds., Handbook of Cultural Geography. London: Sage, 290-299.

Rahnema, M., Bawtree, V. eds. (1997). The post-development reader. London: Zed Press.

Routledge, P (1997). The imagineering of resistance: Pollock Free State and the practice of postmodern politics. Transactions, Institute of British Geographers NS 22:359-376.

Sarmento, J., Azevedo, A.F., Pimenta, J.R. (2006). Ensaios de Geografia Cultural. Porto: Figueirinhas.

Sidaway, J. (2007). Spaces of postdevelopment. Progress in Human Geography 31(3): 345-361.

Watts, M. (2003). Alternative Modern - Development as Cultural Geography. In Anderson, K. et al eds., Handbook of Cultural Geography. London: Sage, 290-299. 